\title{
Rancang Bangun Sistem Informasi Jasa Laundry Pada Rumah Laundry Berbasis Android
}

\author{
Huswatun Hasanah ${ }^{1}$, Rizki Fatullah ${ }^{2}$, Ilham Ilahi ${ }^{3}$ \\ 1,2,3) Fakultas Ilmu Komputer, Universitas Banten Jaya \\ Jln. Syech Nawawi Albantani Kp. Baru Kec. Curung Kota Serang \\ Email: huswatunhasanah@unbaja.ac.id ${ }^{1}$, rizkifath@unbaja.ac.id², \\ ilhamilahi199@gmail.com ${ }^{3}$
}

\begin{abstract}
ABSTRAK
Laundry adalah jasa pencucian pakaian dan kain dengan menggunakan air, detergen, pelembut, dan pewangi pakaian. Jasa laundry dapat membantu meringankan pekerjaan seseorang di tengah kesibukan dan keterbatasan waktu, yang disebabkan padatnya aktivitas sehari-hari menyebabkan mereka tidak sempat untuk mencuci pakaian dan lainnya. Dalam perkembangan teknologi yang berjalan sangat pesat, dengan memanfaatkan teknologi informasi dapat mempermudah kegiatan yang berjalan pada proses pelayanan dan pengelolaan sistem informasi pada Rumah Laundy. Tujuan penelitian ini adalah merancang suatu sistem informasi yang terkomputerisasi berbasis android pada Rumah Laundry yang diperuntukkan dapat membantu petugas atau kasir yang mengelola seluruh proses pelayanan dan pengelolaan sistem informasi yang berjalan pada Rumah Laundry. Metode perancangan sistem yang digunakan dalam penelitian ini yaitu menggunakan metode Waterfall sehingga lebih mudah dikembangkan dan menggunakan UML untuk pemodelan sistem. Hasil penelitian yang di dapat berupa pengelolaan data, pelayanan dan proses pembuatan laporan secara akurat. Kesimpulan pada penelitian ini adalah dengan diterapkan sebuah aplikasi perancangan sistem infromasi jasa laundry pada Rumah Laundry mampu meningkatkan proses pekerjaan dan meningkatkan proses pelayanan secara efesien dan akurat.
\end{abstract}

Kata Kunci: Android, Laundry, Sistem Informasi

\begin{abstract}
Laundry is a service for washing clothes and fabrics using water, detergents, softeners, and clothes deodorizers. Laundry can also help ease a person's work in the midst of busyness and time constraints, which is caused by the density of daily activities causing them not to have time to wash clothes and others. In the development of technology that is running very rapidly, utilizing information technology can facilitate activities that run on the service process and management of information systems at the Laundry House. The purpose of this study is to design an android-based computerized information system at the Laundry House which is intended to help officers or cashiers who manage the entire service process and management of information systems that run at the Laundry House. The system design method used in this research is using the Waterfall method so that it is easier to develop and using UML for system modeling. The results of the research can be in the form of data management, services and the process of making reports accurately. The conclusion in this study is that by applying an application to design a laundry service information system at the Laundry House, it is able to improve the work process and improve the service process efficiently and accurately.
\end{abstract}

Keywords: Android, Laundry, Information System 


\section{Pendahuluan}

Laundry adalah layanan mencuci pakaian dan kain menggunakan air, deterjen, pelembut dan pewangi pakaian. Layanan laundry bukan hanya tempat untuk mencuci pakaian, tetapi juga tempat untuk merawat pakaian agar lebih bersih dan tahan lama. Laundry juga dapat membantu mempermudah pekerjaan seseorang di lingkungan yang sibuk dan waktu terbatas karena intensitas aktivitas sehari-hari membuat mereka tidak punya waktu untuk mencuci pakaian dan sejenisnya.

Saat ini, Laundry telah menjadi peluang usaha bagi masyarakat umum disebabkan tingkat kesibukan yang sangat tinggi pada masyarakat khususnya mahasiswa yang kebanyakkan bermukim di kota besar untuk menuntut ilmu sehingga mereka lebih memilih untuk memanfaatkan jasa laundry (Sari et al., 2017). Justitia et al. (2021) menyatakan usaha Laundry termasuk dalam kategori bisnis dengan perputaran yang cepat, dengan rentang waktu permintaan pelanggan yang pendek. di samping itu, bisnis ini juga merupakan bisnis yang selalu dibutuhkan banyak orang karena mencuci pakaian merupakan kebutuhan primer manusia. Saputra et al., n.d.(2020) menyatakan bahwa pekerjaan rumah tangga, salah satunya adalah mencuci pakaian, merupakan salah satu kegiatan yang menyita waktu. Tidak hanya itu, kegiatan ini dilakukan setiap hari, dan tentunya ketika ada pekerjaan rumah yang terbengkalai tidak akan merasa nyaman untuk ditinggalkan.

Rumah Laundry adalah sebuah usaha rumahan yang bergerak di bidang penyedia layanan jasa laundry yang berlokasi di Kota Serang Provinsi Banten. Dalam menjalankan kegiatannya, perusahaan Rumah Laundry ini masih menggunakan sistem informasi manual. Salah satu bentuk contoh penerapan sistem manual pada perusahaan ini adalah proses transaksi pembayaran pencucian pakaian dimana pelanggan harus menunggu lama untuk menghitung harga pakaian dalam sekali cuci. Selain itu, sistem informasi manual yang masih diterapkan di perusahaan ini rawan sekali terjadi kesalahan atau bahkan kecurangan dalam pencatatan transaksi yang pada akhirnya berdampak pada penyajian laporan pendapatan yang kurang akurat.

Beberapa permasalahan yang ditemui pada Rumah Laundry sebagai dampak dari sistem informasi manual terlihat pada proses transaksi pembayaran dimana kasir kesulitan menghitung harga total cucian terutama jika pelanggan menambahkan beberapa jenis pakaian dalam satu kali cuci, yang tentu saja rawan terjadi kesalahan hitung. Kemudian, kasir kadang lupa untuk mencatat transaksi harian terutama jika kondisi laundry sedang ramai. Pencatatan transaksi yang berulang juga mengkonsumsi banyak kertas, ini mengakibatkan redudansi data yang dikhawatirkan sebuah pencatatan manual berpotensi data transaksi hilang atau rusak. Beberapa kesalahan tersebut berakibat pada pembuatan laporan berisi pendapatan yang tidak akurat dan pada akhirnya akan merugikan perusahaan.

Dalam perkembangan teknologi informasi yang semakin berkembang pesat, untuk membuat sebuah proses sistem informasi menjadi maksimal, diperlukan sebuah sistem dalam mendukung hal tersebut yaitu dengan membuat perancangan sistem informasi jasa laundry berbasis android. Android adalah sebuah sistem operasi untuk perangkat mobile berbasis Linux yang mencakup sistem operasi, middleware dan aplikasi android menyediakan platform terbuka bagi para pengembang untuk menciptakan aplikasi mereka sendiri untuk digunakan oleh berbagai macam piranti bergerak. 
Penelitian terkait perancangan sistem informasi telah dilakukan oleh (Elvionita, 2021) sistem informasi yang dirancang terbukti dapat memaksimalkan kinerja admin dalam mengelolah data panti jompo dengan lebih cepat dan akurat, pemberian informasi kepada masyarakat terkait donasi yang telah diberikan lebih transparan, sedangkan penelitian terkait dengan Sistem Informasi Jasa laundry berbasis android telah dilakukan, seperti aplikasi pelayanan jasa pada Laundry Berbasis Android untuk meningkatkan pelayanan di Bisnis Laundry Pos ((Hoesen \& Manik. Veronica, 2019). Penelitian ini membahas tentang kendala dalam pemesanan laundry. Untuk meningkatkan pelayanan jasa pada bisnis laundry ini, dibuatlah perancangan dan aplikasi pelayanan jasa berbasis android yang diharapkan akan mempermudah dan memberikan kenyamanan untuk pelanggan laundry POS.

Selain itu, ada juga penelitian yang serupa, yaitu penelitian tentang sistem informasi pemesanan Laundry berbasis Android di Kota Palembang (Susanto et al., 2019). Hasil dari pengembangan sistem ini adalah dapat membantu pemilik jasa laundry untuk mempromosikan usahanya serta dapat mempermudah pelanggan dalam mencari tempat laundry terdekat dengan kualitas terbaik.

Dengan fakta tersebut di atas, penulis terdorong untuk membangun sebuah sistem informasi yang berjudul "Rancang Bangun Sistem Informasi Jasa Laundry Pada Rumah Laundry Berbasis Android' agar memberikan kenyamanan dan kemudahan dalam bertransaksi.

\section{Metode Penelitian}

Sistem infomasi berbasis Android ini menggunakan metode pengembangan waterfall. Alasan penggunaan metode waterfall karena tahap - tahap dalam pengembangan sistem pada model ini terstruktur secara jelas. Metode waterfall adalah sebuah metode pengembangan yang bersifat sekuensial dan terdiri dari 4 tahap yang saling terkait dan mempengaruhi (Setiyanto et al., 2018). Adinata et al. (2020) menyebutkan bahwa metode waterfall ini sering disebut juga metode air terjun. Metode ini merupakan metode dengan pendekatan spesifik yang sistematis dan berurutan dalam pengembangan perangkat lunak, dimana sebuah tahapan harus diselesaikan terlebih dahulu sebelum ke tahap berikutnya.

Dalam waterfall, terdapat beberapa tahapan utama yang menggambarkan aktivitas pengembangan perangkat lunak. Model ini melakukan pendekatan secara sistematis dan urut mulai dari level kebutuhan sistem lalu menuju ke tahap analisis, coding, testing dan maintenance.

Seperti namanya, waterfall (air terjun), dalam metode ini langkah-langkahnya disusun berjenjang. Setiap tahapan dalam model ini dilakukan secara berurutan. Selain itu, tahapannya dapat kembali dari satu level ke level sebelumnya. Model ini biasanya digunakan untuk membuat perangkat lunak dalam skala besar dan yang akan digunakan untuk waktu yang lama. 


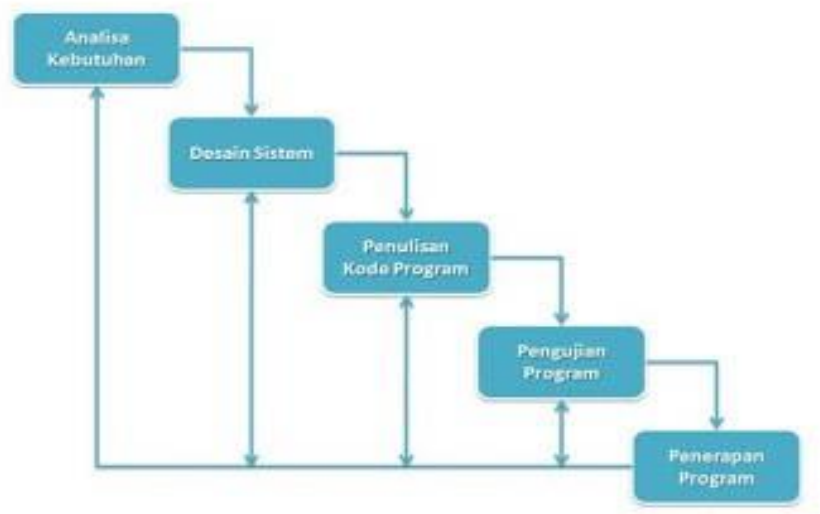

Gambar 1. Metode waterfall

Berikut ini adalah tahap-tahap model Waterfall:

1. Analisis Kebutuhan

Mengumpulkan kebutuhan secara lengkap kemudian dianalisis dan didefinisikan kebutuhan yang harus dipenuhi oleh program yang akan dibangun. Fase ini harus dikerjakan secara lengkap untuk bisa menghasilkan desain yang lengkap.

Setelah dikumpulkan secara lengkap, kebutuhan pun dianalisis. Kebutuhan tersebut harus dipenuhi oleh program yang dibuat. Tahap ini harus diselesaikan dengan baik untuk menghasilkan desain yang lengkap.

2. Design System

Pada tahap ini, pengembang membuat keseluruhan sistem dan menentukan aliran perangkat lunak ke algoritma secara terperinci.

3. Penulisan Kode Program

Tahap dimana semua desain diubah menjadi kode program. Kode program yang dihasilkan berupa modul-modul masih harus digabungkan menjadi satu sistem yang utuh.

4. Pengujian Program

Pada tahap ini, modul yang dibuat akan digabungkan dan diuji. Hal ini dilakukan untuk mengetahui apakah perangkat lunak yang dibuat sesuai dengan struktur dan fungsinya, apakah terdapat kesalahan pada perangkat lunak tersebut atau tidak.

5. Penerapan Program

Pelanggan atau pengguna menguji apakah sistem sudah sesuai dengan yang disetujui.

\section{Hasil dan Pembahasan}

\section{Rancangan Sistem}

Tahap ini merupakan tahap pembahasan dari sistem yang akan dibangun. Rancangan sistem berarti menggambarkan tampilan dan cara kerja dari sistem secara global.

\section{Use Case Diagram}

Use Case merupakan sebuah rangkaian yang berkaitan dengan sistem yang dijalankan oleh admin yang menggambarkan fungsional dari sistem sarana dan 
Unitek : Jurnal Universal Teknologi

Vol. 14 No.2 Juli - Desember 2021

e-ISSN : 2580-2582, p-ISSN: 2089-3957

prasarana agar dapat dimengerti oleh pengguna, fungsi sistem dan menu apa saja yang terdapat dalam sistem.

Adapun, Use Case Diagram sistem informasi jasa laundry pada Rumah Laundry berbasis Android sebagai berikut:

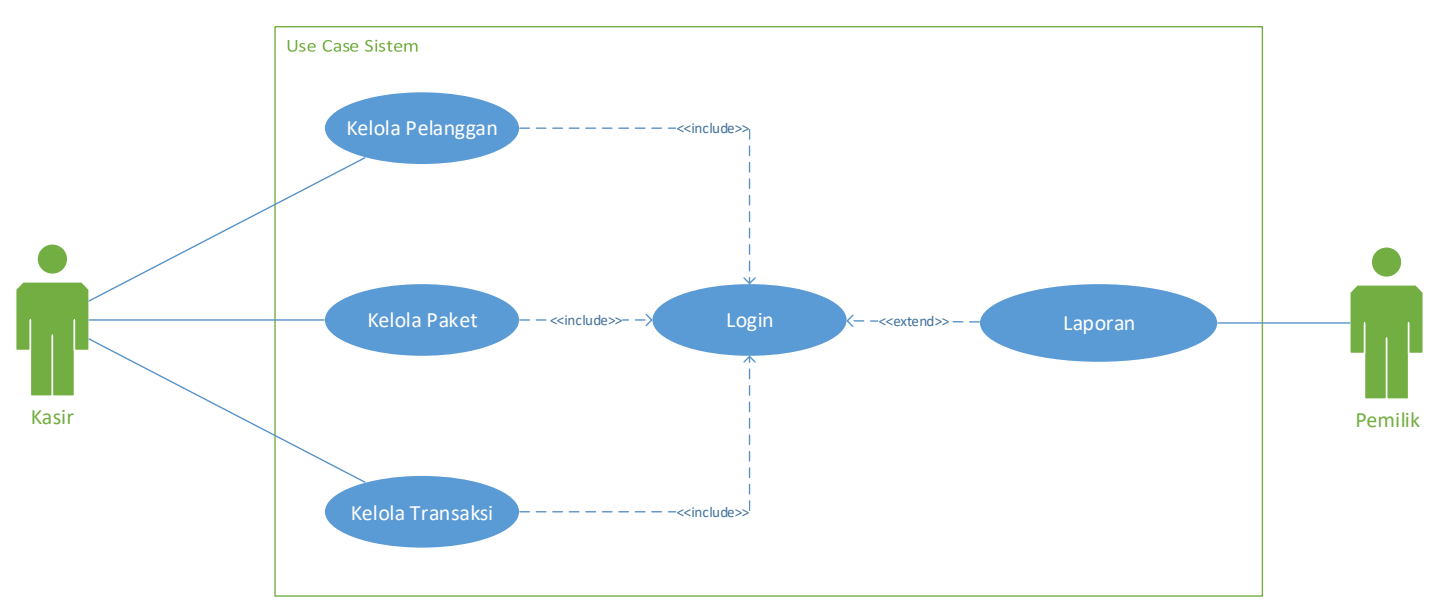

Gambar 2. Use Case Diagram

2. Class Diagram

Class diagram adalah diagam yang digunakan untuk menampilkan beberapa kelas serta paket-paket yang ada dalam sistem/perangkat lunak yang sedang kita gunakan (Magfirah, 2015).

Adapun, Class Diagram sistem informasi jasa laundry pada Rumah Laundry berbasis Android sebagai berikut:

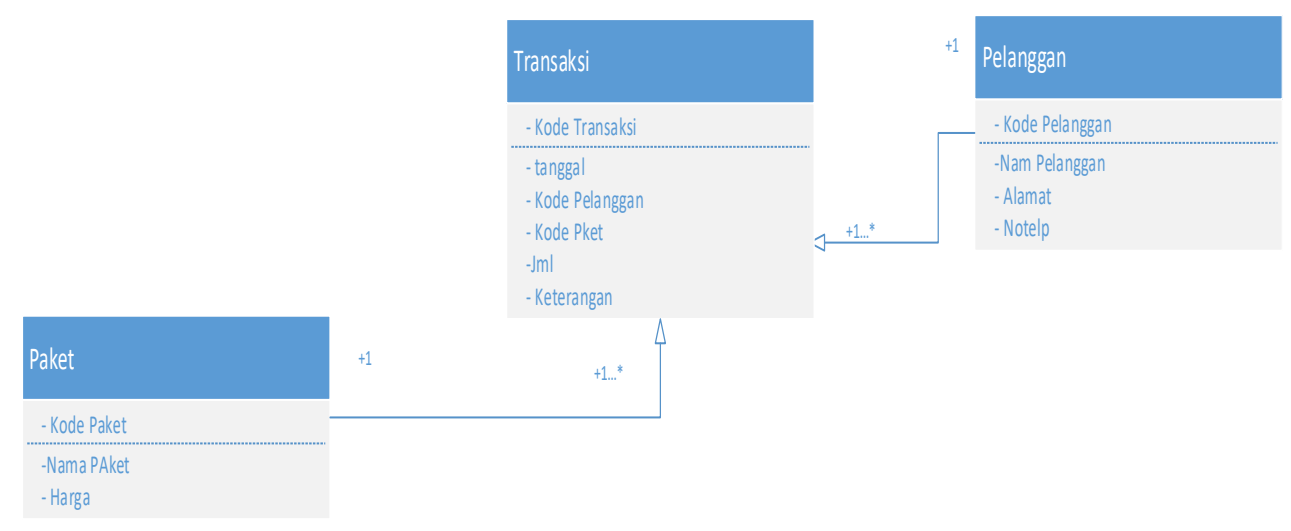

Gambar 3. Class Diagram

\section{Implementasi Sistem}

1. Prosedur Operasional (Manual Book)

Dalam mengoperasikan Aplikasi Laundry harus mengikuti prosedur sebagai berikut :

1). Pastikan sistem komputer sudah siap dioperasikan dengan benar. 
Unitek : Jurnal Universal Teknologi

Vol. 14 No.2 Juli - Desember 2021

e-ISSN : 2580-2582, p-ISSN: 2089-3957

2). Nyalakan server sesuai dengan standar yang telah ditentukan.

3). Pilih aplikasi pada Rumah Laundry pada Handphone.

4). Setelah Tampil layar masukkan halaman login seperti berikut :

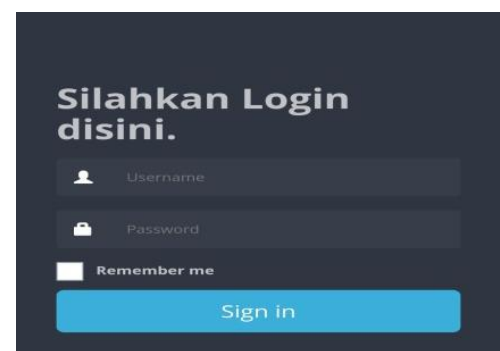

Gambar 4. Tampilan Login

5). Tampilan menu utama terlihat sebagai berikut:

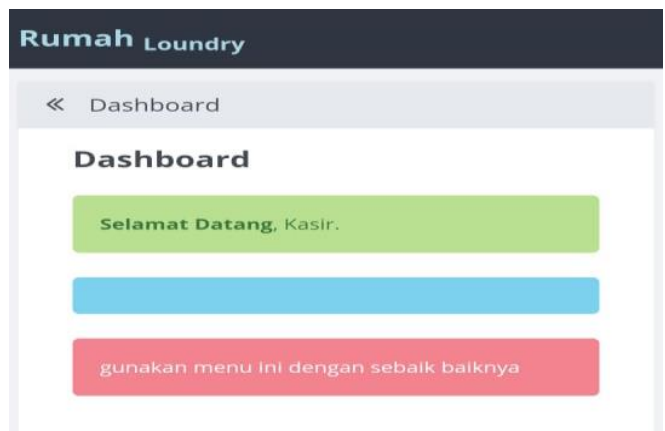

Gambar 5. Tampilan menu utama

6) Selanjutnya, ada tampilan menu customer yang memperlihatkan pelanggan yang menggunakan jasa Laundry. Adapun tampilannya seperti di bawah ini:

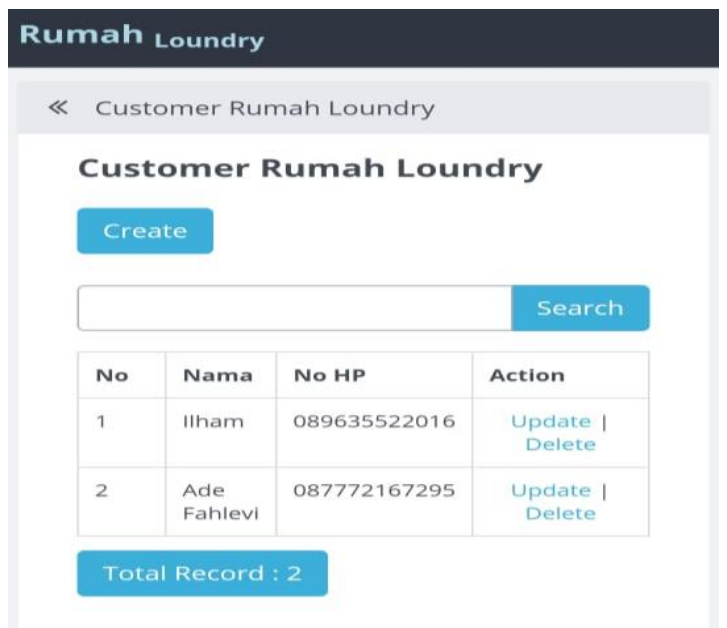

Gambar 6. Tampilan customer 
Unitek : Jurnal Universal Teknologi

Vol. 14 No.2 Juli - Desember 2021

e-ISSN : 2580-2582, p-ISSN: 2089-3957

7) Terdapat tampilan form input customer untuk mengisi biodata pelanggan yang menggunakan jasa Laundry. Tampilannya seperti di bawah ini:

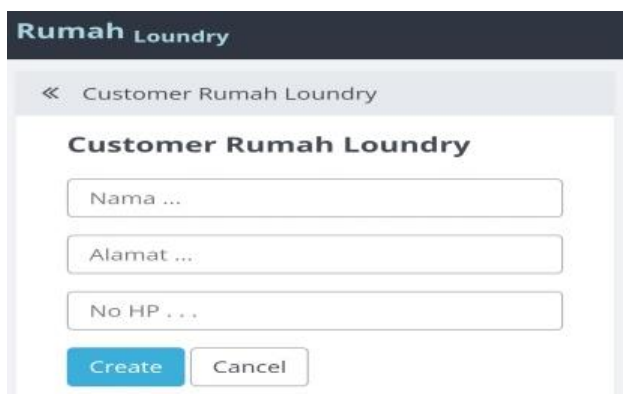

Gambar 7. Tampilan Form Input Customer

8) Selanjutnya, ada tampilan menu tambah transaksi yang berfungsi untuk menginput transaksi yang dilakukan. Berikut adalah tampilannya:

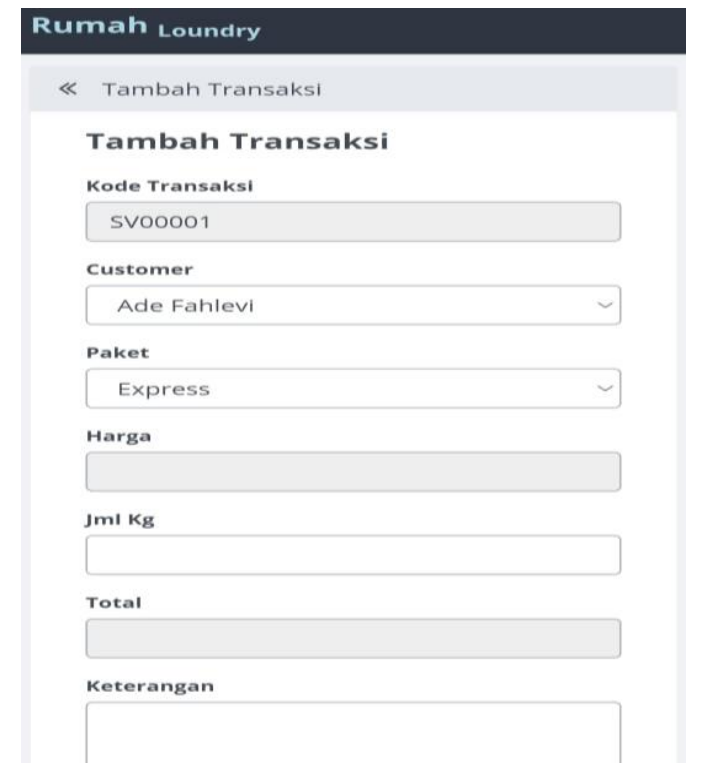

Gambar 8. Tampilan menu tambah transaksi

9) Lalu, muncul tampilan menu paket Laundry untuk menginformasikan paket yang ada pada jasa Laundry ini beserta daftar harganya. Tampilannya adalah sebagai berikut: 
Unitek : Jurnal Universal Teknologi

Vol. 14 No.2 Juli - Desember 2021

e-ISSN : 2580-2582, p-ISSN: 2089-3957

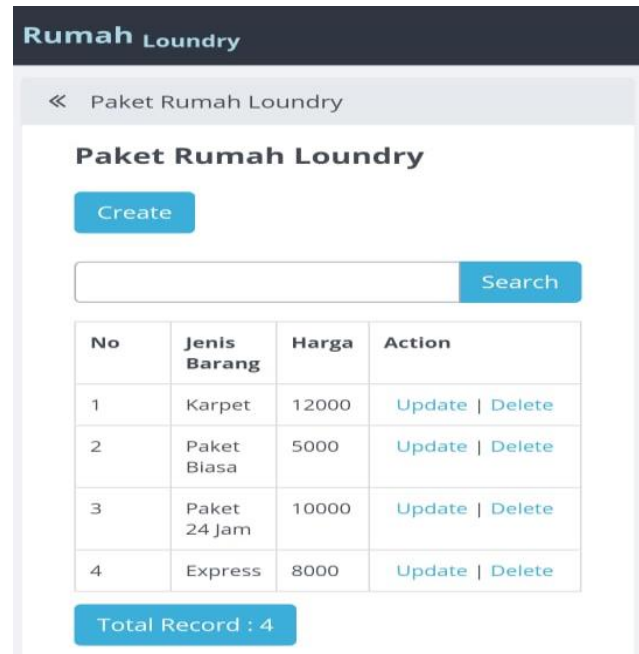

Gambar 9. Tampilan Menu Paket Laundry

10) Selanjutnya, ada tampilan menu form input paket Laundry untuk mengisi apa saja jasa Laundry yang dipilih. Berikut adalah tampilannya:

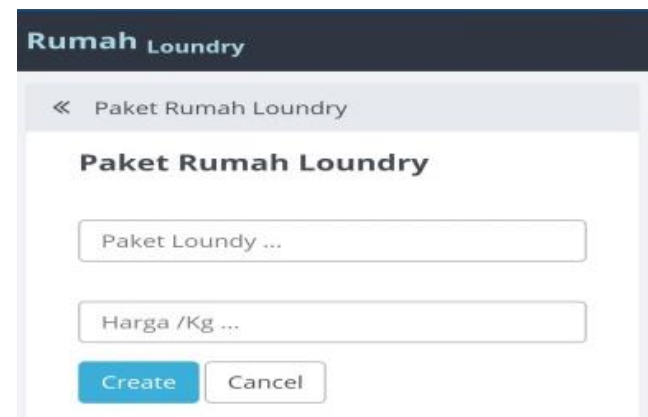

Gambar 10. Tampilan Form Input Paket Laundry

\section{Simpulan}

Berdasarkan penelitian yang telah dilakukan, pengembangan sistem informasi jasa laundry pada Rumah Laundry berbasis android ini dapat membuat pengolahan data menjadi lebih efektif, pencatatan transaksi yang masih manual yang dapat menyebabkan terjadinya kesalahan pencatatan, bahkan berpotensi terjadinya kecurangan seperti manipulasi data atau transaksi yang sengaja tidak dicatat. Selain itu, mempermudah admin dalam mengelola proses pengelolaan data laundry para pelanggan, pencatatan data paket laundry dan transaksi order maupun pengambilan laundry, pembuatan laporan, baik laporan transaksi order laundry, pengambilan laundry, data pelanggan maupun data paket laundry dapat diakses dengan efisien. Dengan sistem yang terkomputerisasi ini juga dapat mempermudah dalam pencarian data. 


\section{Daftar Pustaka}

Adinata, E. B., Wijaya, D. R., \& Hernawati, E. (2020). Aplikasi Laundry Berbasis Android Module Customer Android Based Laundry Aplication Module Customer. 6(2), 1618-1637.

Elvionita, D., \& Sari, F. (2021). Sistem Informasi Pengelolaan Data Panti Sosial Jompo Dhuafa Sayang Ummi Berbasis Website Di Kota Dumai. JURNAL UNITEK, 14(1), 1-9. https://doi.org/10.52072/unitek.v14i1.172

Hoesen, N., \& Manik. Veronica. (2019). Aplikasi Pelayanan Jasa Pada Laundry Berbasis Android Untuk. Jurnal Manajemen Bisnis, 22(1), 82-91.

Justitia, A., Werdiningsih, I., Effendy, F., \& Taufik, T. (2021). Pelatihan dan Pendampingan Digital Marketing bagi UMKM Jasa Laundry menuju UMKM Go Digital. Jurnal Nasional Pengabdian Masyarakat, 2(2), 60-72. https://doi.org/10.47747/jnpm.v2i2.388

Magfirah. (2015). Perancangan Sistem Informasi Usaha Kepariwisataan. April, 8591.

Saputra, I., Naf'an, E., Devita, R., \& Nurhadi. (n.d.). Rancang Bangun Alat Pelipat Baju Sebagai Media Pembelajaran Bagi Anak-Anak Via Smartphone. 13(2), 5968.

Sari, E. N., Handayani, L., \& Saufi, A. (2017). Hubungan Antara Umur dan Masa Kerja dengan Keluhan Musculoskeletal Disorders ( MSDs ) pada Pekerja Laundry Correlation Between Age and Working Periods with Musculoskeletal Disorders ( MSDs ) in Laundry Workers. Jurnal Kedokteran Dan Kesehatan, 13(9), 183-194.

Setiyanto, S., Wahyu Winarno, W., \& Amborowati, A. (2018). Rancang Bangun Sistem Informasi Perpustakaan Berbasis Mobile Pada Sekolah Tinggi Teknologi Dumai. Jurnal Unitek, 11(1), 9-23. https://doi.org/10.52072/unitek.v11i1.25

Susanto, E., Utami, T. H., \& Hermanto, D. (2019). Sistem Informasi Pemesanan Laundry Berbasis Android Di Kota Palembang. JATISI (Jurnal Teknik Informatika Dan Sistem Informasi), 5(2), 158-168. https://doi.org/10.35957/jatisi.v5i2.144 